\title{
THE MODERATOR EFFECT OF RESISTANCE TO CHANGE ON RELATIONSHIP BETWEEN INNOVATION CULTURE AND INNOVATION POTENTIAL: AN IMPLEMENTATION IN TURKISH COMPANIES IN THE CONTEXT OF MULTICULTURALISM
}

\section{DOI: 10.17261/Pressacademia.2019.1092}

PAP- V.9-2019(39)-p.197-202

Yavuz Cakir ${ }^{1}$, Pinar Acar ${ }^{2}$

${ }^{1}$ Bahcesehir University, Graduate School of Social Sciences, 34353, Besiktas, Istanbul, Turkey yvz.ckr@hotmail.com, ORCID: 0000-0001-8036-0484

${ }^{2}$ Beykoz University, Faculty of Business and Administrative Sciences, Business Administration in English, Kavacık, Beykoz, Istanbul, Turkey pinaracar@beykoz.edu.tr, ORCID: 0000-0002-4290-6383

To cite this document

Cakir, Y., Acar, P. (2019). The moderator effect of resistance to change on relationship between innovation culture and innovation potential: an implementation in Turkish companies in the context of multiculturalism. PressAcademia Procedia (PAP), V.9, p.197-202

Permemant link to this document: http://doi.org/10.17261/Pressacademia.2019.1092

Copyright: Published by PressAcademia and limited licenced re-use rights only.

\begin{abstract}
Purpose- In this study, it was aimed to observe the adaptation and reaction of multicultural firms and these firms to the innovation culture of Turkish employees.

Methodology- In our research, firstly, the theoretical basis was established by literature review and then supported by quantitative research method. The sample of the study consisted of 234 Turkish employees from multicultural firms in different sectors. SPSS 20 and PROCESS 3.2 programs were used in this study.

Findings- According to the analysis results, the innovation culture positively affects the innovation potential. However, it has been shown that resistance to change factor weakens this effect. As the resistance factor to change increases, these relationships are adversely affected. Conclusion- Resistance to change has a moderator effect on the impact of innovation culture on innovation potential.
\end{abstract}

Keywords: Innovation culture, resistance to change, innovation potential, multiculturalism, SPSS, process

JEL Codes: M0, M1, O3.

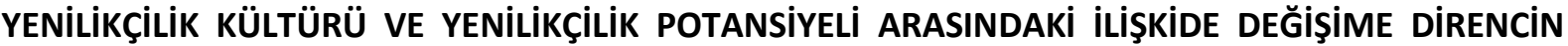 DÜZENLEYICI ETKISI: ÇOKKÜLTÜRLÜ ŞIRKETLERDE BIR UYGULAMA}

ÖZET

Amaç- Bu araştırmayla, çokkültürlü firmalar ve bu firmaların Türk çalışanlarının yenilikçilik kültürüne olan adaptasyon ve tepkisi gözlenmek istenmiştir.

Yöntem- Arasstırmamızda öncelikle literatür taraması yapılarak teorik temel oluşturulmuş sonrasında nicel araştırma yöntemiyle desteklenmiştir. Farklı sektörlerde bulunan ve çokkültürlü yapıda bulunan firmalardan 234 Türk çalışan, araştırmanın örneklemini oluşturmuş̧tur. Bu araştırmada SPSS 20 ve PROCESS 3.2 programları kullanılmıştır.

Bulgular- Analiz sonuçlarına göre, yenilikçilik külttürü yenilikçilik potansiyelini olumlu yönde etkilemektedir. Bununla birlikte, değişime direnç faktörünün bu etkiyi zayıflattığı bulgulara göre ortaya konmuștur. Değișime direnç faktörü arttıkça, bu ilişkiler olumsuz yönde etkilenmektedir.

Sonuç- Yenilikçilik kültürünün yenilikçilik potansiyeline etkisinde değişime direncin düzenleyici (moderatör) etkisi bulunmaktadır.

Anahtar Kelimeler: Yenilikçilik kültürü, değişime direnç, yenilikçilik potansiyeli, çokkültürlülük, SPSS, proses JEL Kodları: M0, M1, O3.

\section{GiRiş}

Yenilikçilik, sadece Ar-Ge, teknik ve fiziksel düzenlemeler gibi somut bileşenlerle açıklanacak bir konu değil, aynı zamanda son otuz yılda diğer aktörler ve kurumlarla işbirliği yapma yeteneğine dayanan ekonomik aktörlerin başarısı için stratejik bir mesele haline gelmiştir (Karakayacı ve Dinçer, 2018). Yenilikçilik veya inovasyon, bazıları bir dizi iç ve dış bilgi ve bilgi kaynağına başvurularak belirlenen farklı yöntemler altında 
gerçekleşir (Doloreux vd, 2018). Şirketler, kurumsal yaşam döngüleri boyunca birden fazla inovasyon türü benimseyebilir, ancak birden fazla inovasyon türünü karıştırmak çoğu zaman karmaşık olarak kabul edilirken, tek bir inovasyon türüne odaklanmak performansın düşmesine neden olabilir (Prange ve Schlegelmilch, 2016, aktaran Lizarelli vd, 2018). Inovasyonun stratejik önemini vurgulayan kuruluşlar, bilgi yaratımı için faydalı bir bağlam sağlayarak inovasyona yönelik yeni ürün veya süreçler olarak somutlaşmaya yönelik ortak çabaları kolaylaştırabilir (Li vd, 2018). Firmalar, mevcut çalışanlarının yanında, alınan veya yapılacak olacak değişimi hayata geçirebilecek, bu değişime adaptasyonu sağlayabilecek ve devamlılığı sağlayabilmek için yeni çalışan bireylere yönelmektedirler. Sonuç olarak, çalışanlar arasında gerçekleştirilen bu değişim işletme içerisindeki kültür boyutunu etkileyecek ve çokkültürlülük olarak tabir edilen, birçok farklı kültürün bir araya gelerek sentezlenen bir yapı meydana gelecektir. Yenilikçilik kültürü kuruluşların sürekli yeteneklerini geliştirmelerine ve yapılarını inovasyona yönelik geliştirmelerine yardımcı olan stratejilerin tanımlanması ve uygulanmasını ifade eder (Ahmed, 1998; aktaran Batz vd., 2018).

\section{LITERATÜR INCELEMESI}

\subsection{Yenilikçilik}

Literatür incelendiğinde, yenilikçilikle ilgili birçok tanımla karşılaşmaktayız. İnovasyon kavramı Türkçe'de 'yeni', 'yenilikçilik' gibi kavramları ifade etse de Latince'de toplumsal ve kültürel alanlarda yeni uygulanmaların kullanılmasını ifade etmektedir (Ustel ve Kabatepe, 2006, Şan ve Bayraktar 2017). Bir yenilik, işletme içi uygulamalarda, iş yeri organizasyonunda veya dış ilişkilerde yeni veya önemli derecede iyileştirilmiş bir ürün (mal veya hizmet), veya süreç, yeni bir pazarlama yöntemi ya da yeni bir organizasyonel yöntemin gerçekleştirilmesidir (Oslo Kılavuzu, 2005). Ayrıca, yenilikçilik sadece yeni çıkarılacak ürünleri değil, geliştirilecek yeni yönetim, teknoloji ve geliştirmeleri de kapsar (Jamrog vd., 2006; aktaran Aksay 2011).

\subsection{Yenilikçilik Kültürü}

Yenilikçilik günümüz iş dünyası için vazgeçilmez bir ögedir ve mevcut bir yeniliğe karşı çalışan bireylerin, kurumun, üst yönetimin ortak bir paydada yer almasıyla sürdürülebilirliği sağlanmaktadır. Bu bakımdan, yazılı olmayan ve kurum içi davranışların hüküm sürdüğü bu kültür anlayışı başarıyı veya başarısızlığı getirecek olup yenilikçiliğin potansiyelini belirleyecek etkenlerden birisi olacaktır. Çünkü kültür, işletme içerisindeki çalışanları o iş̧letmenin amaçlarının gerçekleştirilmesi yolunda birbirine bağlar. (Tekin 2018). Yenilikçi kültürün en önemli yanı esneklik, özgürlük ve takım çalışmasını temel alan bir yapıyı önermesidir (Tunçbilek, 2017). Barnett (1953), Beteille (1977), Rothwell ve Wissema (1986), Mokyr (1991), Herbig ve Miller (1992), Lee (1998), Hofstede (2001), yüksek yenilikçilik kapasitesine sahip toplumların özelliklerini aşağıdaki gibi karakterize etmişlerdir (aktaran Didero vd., 2008). Bunlar; yüksek bireycilik, risk alma istekliliği, uzun döneme odaklıı̆̆ı /adaptasyonu, yüksek ve düşük güç mesafesi, belirsizlikten kaçınma, yeni bilgiye açıklık, sık seyahat, bilime karşı olumlu tutum, yüksek öğrenim düzeyleridir ( aktaran Işık, 2017).

\subsection{Yenilikçilik Potansiyeli}

Yenilikçilik kültürü oluştururken, potansiyeli açığa çıkartmak amacıyla çalışanların yenilikçiliği destekleyecek davranışları geliş̧irmeleri sağlanmalıdır. (Russel, 1989, s. 11-12) a göre bu şartlar; yaratıcı çalışanların hareketlerini desteklemek, yenilikçiliği organizasyon içi sorunlar için bir cevap arama faktörü olarak kullanmak, organizasyonda bireyler arası iletişimi güçlendirmek, yenilikçiliği daha iyi uygulayan farklı organizasyonlarla iletişime geçmek, her türlü fikre açık olmak, yenilikçi fikirlere destekleyici olanaklar sağlamak, yenilikçi girişkenliği destekleyecek uygun orandaki risk faktörlerine karşı bireyleri teşvik etmek, değişimi efektif olarak desteklemek (aktaran Tunçbilek, 2017). İçerisinde mevcut bir potansiyel bulundurmasına rağmen harekete geçmenin asıl önem taşıdığı dünyada, firmalar veya bireyler tarafından gerekli adımların atılması ve gereken gücün açığa çıkartılarak sonuç alınması önemlidir. Çünkü 'Ínovasyon, başarılı bir şekilde oluşturulmuş teknolojik değişimlerin ürünleri olarak karşımıza çıkar' (Ballı ve Güreş̧̧, 2017).

\subsection{Değişime Direnç}

Değişimlerde en büyük faktörlerden birisi şüphesiz o firma bünyesinde çalışan personelin mevcut çalışma şartlarını koruyarak, gerçekleştirilen harekete uyum göstermesi, benimsemesi ve hayata geçirmesidir (Choi ve Ruana, 2011; aktaran Garcia-Cabrera vd., 2014) Değişime direnç şahıs bazlı olduğu zamanlarda; kayıtsızlık, dikine gitme, tekrarlama, hata yapma eğilimi, sessiz kalma, ilgisiz kalma gibi durumlar, örgüt bazlı olursa ise çalışanların herhangi bir risk karşııındaki tazminat isteklerinde yükselme, iş devamlıı̆ııın eksilmesi, sosyal masraflarda artış istekleri, verim düşümü gibi olgularla karşılaşılabilir (Barutçugil, 2004: 173; aktaran Özpehlivan ve Altan).

\section{Şekil 1: Araştırmanın Modeli}

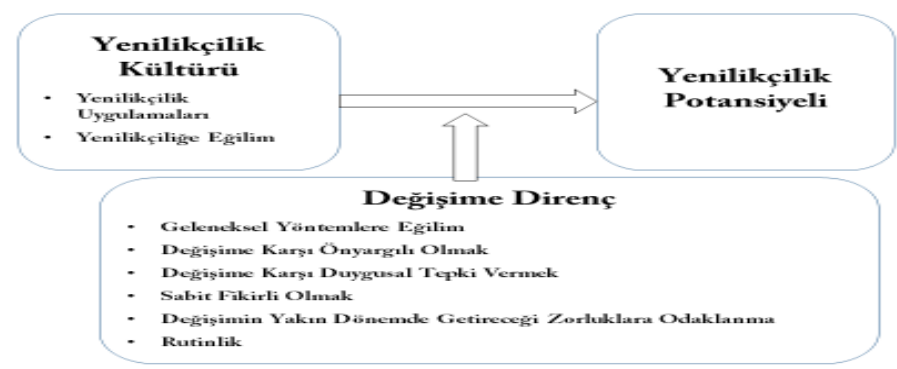




\section{YÖNTEM}

Çalışmanın bu bölümünde, çok kültürlü firmalardaki Türk çalışanların yenilikçilik kültürü, adaptasyon ve değişime direnç olguları saptanmaya çalışılışıtır. Çalışma kapsamında, yabancı ortaklı Türk firmaları, yabancı sermayeli firmaların bütün hisselerini satın alan Türk firmaları veya yabancı bir firma tarafından bütün hisseleri satın alınan Türk firmalarında çalışan Türk personellere ulaşıımıştır. Farklı sektörlerde bulunan ve çok kültrı̈ü yapılarda bulunan firmalardan 234 çalışan, araştırmanın örneklemini oluşturmuştur. Amaç, yenilikçiliği temel alan işletmelerde çalışan bireylerin yabancı kültür içerisinde göstereceği davranış şeklini gözlemlemektir. Veri toplama aracı olarak anket tekniği kullanılmıştır. Anketin ilk bölümü demografik sorulardan oluşmuştur. İkinci bölüm, yenilikçilik kültürü, yenilikçilik potansiyeli ve değişime direnç değişkenlerine ait ölçeklerden oluşmaktadır. Anket soruları 5'li Likert (1.Kesinlikle Katılmıyorum, 2. Katılmıyorum, 3. Kararsızım, 4. Katılıyorum, 5. Kesinlikle Katılıyorum) ölçeğine göre alınmıştır. Yenilikçilik Kültürü Ölçeğinden bağımsız olarak belirlenen alt bileşenlerden Yenilikçilik Uygulamaları ve Yenilikçiliğe Eğilim Dobni (2008) tarafından hazırlanan ve Aksay (2011) tarafından Türkçe'ye uyarlanarak geçerliliği ispat edilen çalışmadan alınmıştır. Yenilikçilik Uygulamaları 15, Yenilikçilik Eğilimi 8 sorudan oluşmaktadır. Yenilikçilik Potansiyeli bağımlı değişken olarak belirlenmiştir ve 6 sorudan oluşmaktadır. Ölçek Dobni (2008)'in çalışmasından alınmıştır. Değişime Direnç ölçeği 16 sorudan oluşmaktadır. Değişime Direnç ölçeğinin soruları Oreg (2003)'ün çalışmasından alınmıştır. Ayden ve Yılmaz (2018) tarafından Türkçe'ye uyarlanmıştır. Bu çalışmada bağımlı değişken Yenilikçilik Potansiyeli olarak alınmış olup, Aksay (2011)'ın çalışmasında yer alan ölçek vasıtasıyla ölçülmüştür. 6 sorudan oluşan bu ölçeğe ait sorular aşağıda yer almaktadır.

\section{BULGULAR}

\subsection{Demografik Bulgular}

Araştırmaya katılan kişileri tanımaya yönelik olarak oluşturulmuş demografik sorulara verilen yanıtların frekans analizi sonuçlarına göre; Araştırmanın cinsiyet dağıımında kadın çalışanların ağırıklı olduğu görülmektedir. Erkek çalışanların oranı \%46,2 iken, kadın çalışanlarda bu oran $\% 53,8^{\prime}$ e çıkmaktadır. Medeni durumlar göz önünde bulundurulduğunda, ankete katılanların \%53' ünün bekar, \%47' sinin evli olduğu görülmektedir. Katılımcıların yaş oranlarında 20-40 yaş aralı̆̆ı ağılık kazanmıştır. $20-29$ yaş aralığındaki çalışan sayısının oranı $\% 41,30-39$ yaş aralığındaki çalışan oranı yakın bir oranda \%41,5'dir. Katılımın daha az sağlandığı 40-49 yaş aralığının oranı \%12 iken, 50-59 yaş aralığında çalışanların oranı \%5,6 da kalmıştır. Ankete katılan kişilerde sektör ayrımı yapılmadığı için yurt genelinde birçok sektörden katılım sağlanmıştır. Ankete katılanlarda en yüksek oranı sağlık sektörü $\% 17,5$ ile sağlarken, perakende gıda sektörü 15,4 , inşaat $\% 13,2$ ve havacılık sektörü $\% 10,7$ ile yer almıştır. Bu sektörler haricinde katıımlar düşük düzeyde yer almıştır. Son olarak, ankete katılan çalışanların pozisyonlarıyla ilgili yapılan değerlendirmede, çalışanların daha çok memur, müşteri danışmanı, uzman ve yönetici olarak kümelendikleri görülmektedir. Araştırmaya katılan çalışanların, \%14, $1^{\prime}$ lik bölümü uzman, \%12'lik kesimi misafir hizmetleri danışmanı, \%11,5'lik kesimi yönetici ve \%11'lik bölümü memur, geri kalanlarsa çeşitli kademelerde çalışan bireylerdir.

\subsection{Geçerlilik ve Güvenilirlik Analizi}

Araştırmada kullanılan ölçekler öncelikle bütünleşik güvenilirlik analizine tabi tutulmuştur. Bütünsel güvenilirlik analizleri sonucu herhangi bir soru analiz dışı kalmadan faktör analizine geçilmiştir. Yenilikçilik eğilimi bütünleșik güvenilirlik analizi sonucu ortaya çıkan Cronbach's alpha değeri 0,935 , faktör analizi sonucu ortaya çıkan KMO değeri 0,935 ve Toplam açıklanan varyans değeri ise 65.723 olarak bulunmuştur. Yenilikçilik eğilimi ölçeği tek boyutta toplanmıştır. Yenilikçilik uygulamaları bütünleşik güvenilirlik analizi sonucu Cronbach's alpha değeri 0,895, faktör analizi sonucu ortaya çıkan KMO değeri 0,918 ve Toplam açıklanan varyans değeri ise 61.897 olarak bulunmuştur. Yenilikçilik uygulamaları ölçeğinden iki gizil (latent) değişken oluşturulmuştur. Faktör analizi sonucu yu11 faktör yüklerinde yakın değerler aldığı için analiz dışı kalmıştır. Yenilikçilik uygulamaları ölçeğinin alt boyutlarının güvenilirlik analizleri sonucu Cronbach's alpha değerleri sırasıyla 0,892 ve $0,885^{\prime}$ dir. Yenilikçilik potansiyeli bütünleşik güvenilirlik analizi sonucu Cronbach's alpha değeri 0,798 , faktör analizi sonucu ortaya çıkan KMO değeri 0,795 ve Toplam açıklanan varyans değeri 51.043 olarak bulunmuştur. Yenilikçilik potansiyeli ölçeği tek boyutta toplanmıştır. Son olarak teorik modelde düzenleyici değişken olarak varsayılan Değişime direnç ölçeğinin bütünleşik güvenilirlik analizi sonucu Cronbach's alpha değeri 0,890, faktör analizi sonucu ortaya çıkan KMO değeri 0,861 ve Toplam açıklanan varyans değeri 68.499 olarak bulunmuştur. Faktör analizi sonucu soru dd6 faktör yüklerinde yakın değerler aldığı için analiz dışı kalmıştır. Değişime direnç ölçeğinin alt boyutlarının güvenilirlik analizi sonucu Cronbach's alpha değerleri sırasıyla 0,879, 0,772, 0,912 ve 0,433'tür. Cronbach's alpha değerinin 0,70 olan sınırın altında kaldığı için 4. boyut (soru dd3, dd4 ve dd15) analiz dışı kalmıştır. Bu durumda değişime direnç ölçeğinden 3 gizil (latent) değişken oluşturulmuştur. Faktör yükleri açısından incelendiğinde Yenilikçilik uygulamaları: 0,570-0,819 ve Değişime direnç: 0,538-0,892 arası değerler almıştır.

\subsection{Korelasyon ve Regresyon Analizi}

Araştırmanın temel varsayımı sonucu oluşturulan teorik çerçevenin içerisindeki değişkenler arasındaki ilişkiler korelasyon analizine tabi tutulmuştur. Yenilikçilik potansiyeli ile yenilikçilik uygulamaları arasında pozitif bir korelasyon bulunmaktadır. Gizil (Latent) değişkenlerden Altyapı ile Yenilikçilik potansiyeli 0,99 güven seviyesinde 0,631 değeri ile anlamlı bulunmuştur. Gizil (Latent) değişkenlerden Adaptasyon ile Yenilikçilik potansiyeli 0,99 güven düzeyinde 0,684 değeri ile anlamlı bulunmuştur.

Değişime direnç ve yenilikçilik uygulamaları arasında pozitif bir korelasyon bulunmaktadır. Adaptasyon gizil değişkeni ile Sabit fikirli olmak arasındaki ilişki 0,95 güven seviyesinde 0,149 değeri ile anlamlı bulunmuştur. Altyapı gizil değişkeni ile Sabit fikirli olmak arasındaki ilişki 0,95 güven seviyesinde 0,140 değeri ile anlamlı bulunmuştur. Bulgular sonucu yenilikçiliğe eğilim ve yenilikçilik potansiyeli arasında pozitif korelasyon bulunmaktadır. Yenilikçiliğe eğilim ve yenilikçilik potansiyeli arasındaki ilişki 0,99 güven düzeyinde 0,630 değeri ile anlamlı bulunmuştur.

Yenilikçilik potansiyelinin moderatör değişken olan Değişime direncin alt boyutlarıla olan korelasyon analizinin bulguları incelendiğinde; Yenilikçilik potansiyelinin Geleneksel yöntemlere eğilim gizil değişkeni ile arasında negatif korelasyon bulunduğu tespit edilmiştir. Geleneksel yöntemlere eğilim gizil değişkeni ile yenilikçilik potansiyeli 0,99 güven seviyesinde $-0,217$ değeri ile anlamlı bulunmuştur. 
H1: Yenilikçilik Kültürü ve Yenilikçilik Potansiyeli arasında anlamlı ve pozitif yönde bir ilişki vardır.

H2: Yenilikçilik Kültürü ve Değişime Direnç arasında anlamlı bir ilişki vardır.

H3: Değişime Direnç ve Yenilikçilik Potansiyeli arasında anlamlı ve negatif yönde bir ilişki vardır.

Analizlerin bulgularına göre $\mathrm{H} 1$ hipotezi desteklenmiştir. Ayrıca araştırmanın H2 ve H3 hipotezleri kısmi olarak desteklenmiştir.

Yenilikçilik kültürünün yenilikçilik potansiyeline ilişkin regresyon analizi

Analiz sonuçlarına göre Yenilikçilik Kültürü Yenilikçilik potansiyelinin $\left(R^{2}=0,511\right) \% 51,1^{\prime}$ sını açıklamaktadır. Ayrıca, modelin anlamlılık düzeyi ,000 olduğu için H4 hipotezi 0,95 güven seviyesinde kısmen desteklenmektedir. F değeri ise 80,241 olarak bulunmuştur. Altyapı ve Yenilikçilik eğilimi gizil (latent) değişkenleri 0,00 ve 0,02 değerlerinde istatistiksel açıdan anlamlı bulunmuştur.

Değişime direncin yenilikçilik potansiyeline etkisine ilişkin regresyon analizi

Analiz sonuçlarına göre Değişime direnç Yenilikçilik potansiyelinin $\left(R^{2}=0,077\right) \% 7,7$ 'sini açıklamaktadır. Modelin anlamlılı düzeyi, 0,000 olduğu için 0,95 seviyesinde anlamlı bulunmuştur. $F$ değeri 6.387 olarak bulunmuştur ancak $R$ square değeri çok düşük olduğu için modelin açıklama gücünün zayıf olduğu sonucu ortaya çıkmıştır. Değişime direnç 2 ve 3 gizil (latent) değişkenleri 0,001 ve 0,007 değerlerinde anlamlı bulunmuştur.

Yenilikçilik kültürünün değişime dirence etkisine ilişkin regresyon analizi

Bulgulara göre Yenilikçilik kültürü Değişime direncin alt boyutlarından Geleneksel yöntemlere eğilimin $\left(R^{2}=0,028\right) \% 2,8^{\prime}$ ini açıklamaktadır. Modelin anlamlılık düzeyi, 0,091 olduğu için 0,90 seviyesinde anlamlı bulunmuştur. $F$ değeri 2,184 olarak bulunmuştur ancak $R$ square değeri çok düşük olduğu için modelin açıklama gücünün zayıf olduğu sonucu ortaya çıkmıştır. Altyapı ve Adaptasyon gizil değişkenleri 0,043 ve 0,019 değerlerinde istatistiksel açıdan anlamlı bulunmuştur.

\subsection{Moderatör etkiyi ölçen Process tabanlı analiz}

H4: Yenilikçilik Kültürünün Yenilikçilik Potansiyeline etkisinde Değişime Direncin düzenleyici (moderatör) etkisi bulunmaktadır.

Geleneksel yöntemlere eğilimin, altyapının yenilikçilik potansiyeline etkisi üzerindeki düzenleyici rolüne ilişkin PROCESS analiz

Analiz sonuçlarına göre öncelikle değişime direnç2 ile yenilikçilik potansiyeli arasındaki ilişkiyi modelin üçüncü satırında p:0,0000 anlamlılık düzeyi ile görmekteyiz. Bağımlı ve bağımsız değişkenlerin arasındaki ilişkinin anlamlı olması düzenleyici etkiyi ölçmek için ön koşulu oluşturmaktadır. Diğer taraftan coefficient değerinin -0,7930 olduğu tespit edilmiştir. Bu değer modelde değişime direnç2 ile yenilikçilik potansiyeli arasında negatif yönlü bir ilişki olduğunu ortaya koymaktadır. Modelin son satırındaki kesişim (yenuyg1*ddir2) değerlerini incelediğimizde p: 0,0000 değeri 0,05'ten küçük olduğu için model anlamlı bulunmuştur.

Conditional effect değerleri x ve y arasındaki ilişkide moderatör etkinin farklı düzeylerdeki etkisini ortaya koymaktadır. Değişime direnç2'nin düzenleyici etkisi sırasıyla düşük düzey: 1,2500 etkisi 0,3817 , orta düzey:2,0000 etkisi 0,5033 ve yüksek düzey:3,2500 etkisi 0,7059 olarak bulunmuştur. P değeri düşük, orta ve yüksek seviyede 0,0000 olduğu için değişime direnç2'nin tüm düzeylerde anlamlı bir etkiye sahip olduğu ortaya çıkmıştır.

Değişime karşı duygusal tepki vermenin, altyapının yenilikçilik potansiyeline etkisi üzerindeki düzenleyicilik etkisine ilişkin PROCESS analizi

Analiz sonuçlarına göre öncelikle değişime direnç1 ile yenilikçilik potansiyeli arasındaki ilişkiyi modelin üçüncü satırında p:0,0016 anlamlılık düzeyi ile görmekteyiz. Bağımlı ve bağımsız değişkenlerin arasındaki ilişkinin anlamlı olması düzenleyici etkiyi ölçmek için ön koşulu oluşturmaktadır. Diğer taraftan coefficient değerinin -0,4620 olduğu tespit edilmiştir. Bu değer modelde değişime direnç1 ile yenilikçilik potansiyeli arasında negatif yönlü bir ilişki olduğunu ortaya koymaktadır. Modelin son satırındaki kesişim (yenuyg1*ddir1) değerlerini incelediğimizde p: 0,0130 değeri 0,05'ten küçük olduğu için model anlamlı bulunmuştur.

Conditional effect değerleri x ve y arasındaki ilişkide moderatör etkinin farklı düzeylerdeki etkisini ortaya koymaktadır. Değişime direnç1'in düzenleyici etkisi sırasıyla düşük düzey:1,7200 etkisi 0,4759, orta düzey:2,6000 etkisi 0,5544 ve yüksek düzey:3,8000 etkisi 0,6614 olarak bulunmuştur. P değeri düşük, orta ve yüksek seviyede 0,0000 olduğu için değişime direnç1'in tüm düzeylerde anlamlı bir etkiye sahip olduğu ortaya çıkmıştır.

Sabit fikirli olmanın, altyapının yenilikçilik potansiyeline etkisi üzerindeki düzenleyicilik etkisine ilişkin PROCESS analiz

Analiz sonuçlarına göre öncelikle değişime direnç3 ile yenilikçilik potansiyeli arasındaki ilişkiyi modelin üçüncü satırında p:0,0006 anlamlılık düzeyi ile görmekteyiz. Bağımlı ve bağımsız değişkenlerin arasındaki ilişkinin anlamlı olması düzenleyici etkiyi ölçmek için ön koşulu oluşturmaktadır. Diğer taraftan coefficient değerinin -0,4782 olduğu tespit edilmiştir. Bu değer modelde değişime direnç3 ile yenilikçilik potansiyeli arasında negatif yönlü bir ilişki olduğunu ortaya koymaktadır. Modelin son satırındaki kesişim (yenuyg1*ddir3) değerlerini incelediğimizde p: 0,0007 değeri 0,05’ten küçük olduğu için model anlamlı bulunmuştur.

Conditional effect değerleri x ve y arasındaki ilişkide moderatör etkinin farklı düzeylerdeki etkisini ortaya koymaktadır. Değişime direnç3'ün düzenleyici etkisi sırasıyla düşük düzey:1,6667 etkisi 0,3964, orta düzey: 3,0000 etkisi 0,5553 ve yüksek düzey:4,0000 etkisi 0,6744 olarak bulunmuştur. $P$ değeri düşük, orta ve yüksek seviyede 0,0000 olduğu için değişime direnç3'ün tüm düzeylerde anlamlı bir etkiye sahip olduğu ortaya çıkmıştır.

Geleneksel yöntemlere olan eğilimin, adaptasyonun yenilikçilik potansiyeline etkisi üzerindeki düzenleyicilik etkisine ilişkin PROCESS analizi 
Analiz sonuçlarına göre öncelikle değişime direnç2 ile yenilikçilik potansiyeli arasındaki ilişkiyi modelin üçüncü satırında p:0,0001 anlamlılık düzeyi ile görmekteyiz. Bağımlı ve bağımsız değişkenlerin arasındaki ilişkinin anlamlı olması düzenleyici etkiyi ölçmek için ön koşulu oluşturmaktadır. Diğer taraftan coefficient değerinin -0,5796 olduğu tespit edilmiştir. Bu değer modelde değişime direnç2 ile yenilikçilik potansiyeli arasında negatif yönlü bir ilişki olduğunu ortaya koymaktadır. Modelin son satırındaki kesişim (yenuyg2*ddir2) değerlerini incelediğimizde p: 0,0016 değeri 0,05'ten küçük olduğu için model anlamlı bulunmuştur.

Conditional effect değerleri x ve y arasındaki ilişkide moderatör etkinin farklı düzeylerdeki etkisini ortaya koymaktadır. Değişime direnç2'nin düzenleyici etkisi sırasıyla düşük düzey: 1,2500 etkisi 0,4457, orta düzey: 2,0000 etkisi 0,5338 ve yüksek düzey: 3,2500 etkisi 0,6806 olarak bulunmuştur. P değeri düşük, orta ve yüksek seviyede 0,0000 olduğu için değişime direnç2'nin tüm düzeylerde anlamlı bir etkiye sahip olduğu ortaya çıkmıştır.

Değişime karşı duygusal tepki vermenin, adaptasyonun yenilikçilik potansiyeline etkisi üzerindeki düzenleyicilik etkisine ilişkin PROCESS analizi

Analiz sonuçlarına göre öncelikle değişime direnç1 ile yenilikçilik potansiyeli arasındaki ilişkiyi modelin üçüncü satırında p:0,0032 anlamlılık düzeyi ile görmekteyiz. Bağımlı ve bağımsız değişkenlerin arasındaki ilişkinin anlamlı olması düzenleyici etkiyi ölçmek için ön koşulu oluşturmaktadır. Diğer taraftan coefficient değerinin -0,4173 olduğu tespit edilmiştir. Bu değer modelde değişime direnç1 ile yenilikçilik potansiyeli arasında negatif yönlü bir ilişki olduğunu ortaya koymaktadır. Modelin son satırındaki kesişim (yenuyg2*ddir1) değerlerini incelediğimizde p: 0,0140 değeri 0,05'ten küçük olduğu için model anlamlı bulunmuştur.

Conditional effect değerleri x ve y arasındaki ilişkide moderatör etkinin farklı düzeylerdeki etkisini ortaya koymaktadır. Değişime direnç1'in düzenleyici etkisi sırasıyla düşük düzey:1,7200 etkisi 0,5210, orta düzey: 2,6000 etkisi 0,5946 ve yüksek düzey:3,8000 etkisi 0,6950 olarak bulunmuştur. P değeri düşük, orta ve yüksek seviyede 0,0000 olduğu için değişime direnç1'in tüm düzeylerde anlamlı bir etkiye sahip olduğu ortaya çıkmıştır.

Sabit fikirli olmanın, adaptasyonun yenilikçilik potansiyeline etkisi üzerindeki düzenleyici rolüne ilişkin PROCESS analizi

Analiz sonuçlarına göre öncelikle değişime direnç3 ile yenilikçilik potansiyeli arasındaki ilişkiyi modelin üçüncü satırında p:0,0000 anlamlılık düzeyi ile görmekteyiz. Diğer taraftan coefficient değerinin -0,5423 olduğu tespit edilmiştir. Bu değer modelde değişime direnç3 ile yenilikçilik potansiyeli arasında negatif yönlü bir ilişki olduğunu ortaya koymaktadır. Modelin son satırındaki kesişim (yenuyg2*ddir3) değerlerini incelediğimizde p: 0,0001 değeri 0,05'ten küçük olduğu için model anlamlı bulunmuştur.

Conditional effect değerleri x ve y arasındaki ilişkide moderatör etkinin farklı düzeylerdeki etkisini ortaya koymaktadır. Değişime direnç3'ün düzenleyici etkisi sırasıyla düşük düzey: 1,6667 etkisi 0,4576 , orta düzey: 3,0000 etkisi 0,6297 ve yüksek düzey: 4,0000 etkisi 0,7587 olarak bulunmuştur. P değeri düşük, orta ve yüksek seviyede 0,0000 olduğu için değişime direnç3'ün tüm düzeylerde anlamlı bir etkiye sahip olduğu ortaya çıkmıştır.

Geleneksel yöntemlere olan eğilimin, yenilikçilik eğiliminin yenilikçilik potansiyeline etkisi üzerindeki düzenleyici rolüne ilişkin PROCESS analizi

Analiz sonuçlarına göre öncelikle değişime direnç2 ile yenilikçilik potansiyeli arasındaki ilişkiyi modelin üçüncü satırında p:0,0000 anlamlılık düzeyi ile görmekteyiz. Diğer taraftan coefficient değerinin -0,9159 olduğu tespit edilmiştir. Bu değer modelde değişime direnç2 ile yenilikçilik potansiyeli arasında negatif yönlü bir ilişki olduğunu ortaya koymaktadır. Modelin son satırındaki kesişim (yenegil*ddir2) değerlerini incelediğimizde p: 0,0000 değeri 0,05'ten küçük olduğu için model anlamlı bulunmuştur.

Conditional effect değerlerine göre değişime direnç2'nin x ve y üzerindeki düzenleyici etkisi sırasıyla düşük düzey: 1,2500 etkisi 0,3476, orta düzey: 2,0000 etkisi 0,4959 ve yüksek düzey: 3,2500 etkisi 0,7431 olarak bulunmuştur. $P$ değeri düşük, orta ve yüksek seviyede 0,0000 olduğu için değişime direnç2'nin tüm düzeylerde anlamlı bir etkiye sahip olduğu ortaya çıkmıştır.

Değişime karşı duygusal tepki vermenin, yenilikçilik eğiliminin yenilikçilik potansiyeline etkisi üzerindeki düzenleyici rolüne ilişkin PROCESS analizi

Analiz sonuçlarına göre öncelikle değişime direnç1 ile yenilikçilik potansiyeli arasındaki ilişkiyi modelin üçüncü satırında p:0,0000 anlamlılık düzeyi ile görmekteyiz. Diğer taraftan coefficient değerinin -0,5948 olduğu tespit edilmiştir. Bu değer modelde değişime direnç1 ile yenilikçilik potansiyeli arasında negatif yönlü bir ilişki olduğunu ortaya koymaktadır. Modelin son satırındaki kesişim (yenegil*ddir1) değerlerini incelediğimizde p: 0,0001 değeri 0,05'ten küçük olduğu için model anlamlı bulunmuştur.

Conditional effect değerlerine göre değişime direnç1'in modeldeki x ve y üzerindeki düzenleyici etkisi sırasıyla düşük düzey: 1,7200 etkisi 0,4283 , orta düzey: 2,6000 etkisi 0,5413 ve yüksek düzey: 3,8000 etkisi 0,6953 olarak bulunmuştur. P değeri düşük, orta ve yüksek seviyede 0,0000 olduğu için değişime direnç1'in tüm düzeylerde anlamlı bir etkiye sahip olduğu ortaya çıkmıştır.

Sabit fikirli olmanın, yenilikçilik eğiliminin yenilikçilik potansiyeline etkisi üzerindeki düzenleyici rolüne ilişkin PROCESS analizi

Analiz sonuçlarına göre öncelikle değişime direnç3 ile yenilikçilik potansiyeli arasındaki ilişkiyi modelin üçüncü satırında p:0,0000 anlamlılık düzeyi ile görmekteyiz. Diğer taraftan coefficient değerinin -0,6149 olduğu tespit edilmiştir. Bu değer modelde değişime direnç3 ile yenilikçilik potansiyeli arasında negatif yönlü bir ilişki olduğunu ortaya koymaktadır. Modelin son satırındaki kesişim (yenegil*ddir3) değerlerini incelediğimizde p: 0,0000 değeri 0,05'ten küçük olduğu için model anlamlı bulunmuştur.

Conditional effect değerlerine göre değişime direnç3'ün modeldeki x ve y üzerindeki düzenleyici etkisi sırasıyla düşük düzey: 1,6667 etkisi 0,3742, orta düzey: 3,0000 etkisi 0,5795 ve yüksek düzey: 4,0000 etkisi 0,7334 olarak bulunmuştur. P değeri düşük, orta ve yüksek seviyede 0,0000 olduğu için değişime direnç3'ün tüm düzeylerde anlamlı bir etkiye sahip olduğu ortaya çıkmıştır. Analiz sonuçlarına göre H7 hipotezi desteklenmiştir. 


\section{SONUÇ VE ÖNERILER}

Literatürde yenilikçilik olgusu farklı şekillerde ele alınmış olsa da çok kültürlü Türk firmalarının yapmış oldukları değişimlerin bireyler üzerindeki etkisi hakkında pek çalışma bulunmamaktadır. Bu bağlamda yapılan çalışmada, farklı kültürlerle bir araya geldiği zaman Türk çalışanların nasıl etkilendikleri ve davranışlarına nasıl yansıdığı araştırılmıştır. Çalışmanın başında tek başlıkta hipotezlere konu olmuş olan yenilikçilik kültürü ve değişime direnç ölçekleri göz önünde bulundurularak hipotezler tekrar oluşturulmuştur. Bu bağlamda görülmektedir ki; çok kültürlü firmalarda çalışan Türk bireyler alışkın olduğu yaşam şeklini değiştirmekte güçlük çekmekte, bu bakımdan yapılmak istenen veya istenebilecek değişimi istememektedir. Bu bakımdan çalışanlara sağlanacak adaptasyon süreci, alıştırma, değişen veya değişmekte olan kültürün eğitimi gibi destekler sağlanarak, çalışanların değişime daha uyumlu hale getirilmesi sağlanabilir. Analiz sonuçlarının belirttiği gibi, organizasyonların gerçekleştirmek istedikleri hızıı kültür veya yönetim gibi geçişler çalışanlar tarafından olumsuz geri bildirimle sonuçlanabilir. Bu çerçevede, çok kültürlü firmalardaki türk çalışanların, yeni oluşacak kültür ve etkileşim yapısına değişime direnç tutumlarının azaltılması veya ortadan kaldırılması için çalışmalar yapılarak bu konuda daha iyi sonuçlar elde edilebileceği söylenebilir

\section{KAYNAKÇA}

Batz A., Kunath M., Winkler H., 2018. Discrepancies between cluster services and SMEs' needs constraining the creation of a culture of innovation amidst industry 4.0. LogForum 14 (3), 387-405,

Doloreux D., Shearmur R., Rodrıguez M.,2018, Internal R\&D And External Informatıon In Knowledge-Intensıve Busıness Service Innovatıon: Complements, Substitutes Or Independent, Technological and Economic Development of Economy ISSN: 2029-4913 / eISSN: $2029-4921$ 2018 Volume 24 Issue 6: 2255-2276

García-Cabrera A. M., García-Barba Hernández F., 2014, Differentiating the Three Components of Resistance to Change: The Moderating Effect of Organization-Based Self-Esteem on the Employee Involvement-Resistance Relation, HUMAN RESOURCE DEVELOPMENT QUARTERLY,, vol. 25, no. 4, Winter 2014 (c) 2014 Wiley Periodicals, Inc.

Karakayacı Ö., Dinçer İ., 2018, Social Networks and Innovation in Industrial Clusters: A Study in case of Turkish Industrial Clusters, 2018 Yıldız Technical University, Faculty of Architecture, cilt vol. 13- sayı no. 3

Letícia Lizarelli F., de Toledo J. C., Alliprandini D. H., 2018, Integration mechanisms for different types of innovation: case study in innovative companies, Review of Business Management, ISSN 1806-4892

Li Y., Wang M., Van Jaarsveld D. D., Lee G. K., Ma D. G., 2018, From Employee-Experıenced High-Involvement Work System To Innovatıon: An Emergence-Based Human Resource Management Framework, Academy of Management Journal 2018, Vol. 61, No. 5, 2000-2019.

Özpehlivan M., Altan S., 2018, Bilişim Sektöründe Dönüştürücü Liderliğin, Değişime Direnç Ve Yenilikçiliğe Etkisi: İstanbul ilii Örneği, Turkish Studies Economics, Finance and Politics, Volume 13/22, Summer 2018, p. 417-436

Pekdemir, I ve Koçoğlu, M. 2014. İşkoliklik ile iş yaşam dengesi arasındaki ilişkide kişilik özelliklerinin aracılık rolü üzerine bir araştırma. AïÜ Sosyal Bilimler Enstitüsü Dergisi, 14(1):309-337.

Yavuz Konokman G., Yokuş G., Yankar Yelken T., 2016, Yenilikçi Materyal Tasarlamanın Sınıf Öğretmeni Adaylarının Yenilikçilik Düzeylerine Etkisi, Bartın Üniversitesi Eğitim Fakültesi Dergisi Cilt 5, Sayı 3, s. 857-878, Ekim 2016

Zagan, C. (2015). Foucault and parrhesia: the relationship between philosophy and politics. Journal of Romanian Literary Studies, 7:478-483. 